\title{
Analisis Kepuasan Pelanggan Dengan Integrasi Servqual Dan Model Kano Untuk Meningkatkan Mutu Pelayanan Transportasi Online
}

\author{
Uyuunul Mauidzoh ${ }^{1}$, Esa Rengganis $S^{2}$ \\ ${ }^{1,2)}$ Program Studi Teknik Industri, Sekolah Tinggi Teknologi Adisutjipto \\ Jl. Janti Blok R Lanud Adisutjipto \\ Email: farahzizy@gmail.com, esarengganisstta@gmail.com
}

\begin{abstract}
ABSTRAK
Di era modern seperti saat ini alat transportasi dan komunikasi tidak bisa dipisahkan dari kehidupan manusia. Karena dua hal tersebut sering digunakan untuk mempermudah segala pekerjaan manusia. Kecanggihan alat transportasi di abad 21 tidak dapat terbendung lagi. Semakin banyaknya transportasi online berdampak pada semakin ketatnya persaingan. Faktor yang menjadi penyebab terjadinya hal tersebut yakni adanya persaingan harga dan banyaknya alternatif pilihan jasa tranportasi online. Penelitian ini bertujuan untuk mengetahui karakteristik layanan transportasi online yang dibutuhkan oleh masyarakat Yogyakarta. Menentukan kondisi kesenjangan kualitas layanan transportasi online yang ada di masyarakat Yogyakarta. Selain itu juga untuk mengetahui kriteria yang mempengaruhi kepuasan konsumen transportasi online dengan menggunakan model Kano yaitu must be requirement, one dimensionel requirement dan attractive requirement. Dengan metode Servqual didapatkan bahwa gap skor untuk 21 atribut layanan yang diukur dalam penelitian ini menghasilkan nilai yang negatif, dan 2 atribut pelayanan menghasilkan nilai positif. Integrasi Kano model ke dalam Servqual berimplikasi pada perubahan yang berarti juga terjadi perubahan prioritas urutan atribut pelayanan yang perlu diperbaiki. Terdapat 13 atribut pelayanan transportasi online yang perlu di-improve yaitu atribut yang merupakan irisan antara 'weak attributes' yang didapatkan dari perhitungan Servqual dengan yang berkategori 'attractive', 'one-dimensional' dan "must be".
\end{abstract}

Kata kunci: kepuasan pelanggan, transportasi online, servqual, model kano

\begin{abstract}
In the modern era as it is today, transportation and communication cannot be separated from human life. Because these two things are often used to facilitate all human work. The sophistication of transportation in the 21st century cannot be stopped. The increasing number of online transportation has an impact on increasingly intense competition. The factors causing this are price competition and the many alternative choices of online transportation services. This study aims to determine the characteristics of online transportation services needed by the people of Yogyakarta. Determine the gap quality in the quality of online transportation services in the Yogyakarta community. In addition, to find out the criteria that affect online transportation consumer satisfaction using the Kano model, namely must be requirements, one dimension requirements and attractive requirements. The Servqual method it was found that the gap score for the 21 service attributes measured in this study produced a negative value, and 2 service attributes produced a positive value. The integration of the Kano model into Servqual has implications for changes that also mean a change in priority order of service attributes that need to be improved. There are 13 attributes of online transportation services that need to be improved, they are slices between 'weak attributes' obtained from Servqual calculations and those that are categorized as 'attractive', 'one-dimensional' and "must be".
\end{abstract}

Keywords: customer satisfaction, online transportation, servqual, kano model

\section{PENDAHULUAN}

Di era modern ini alat transportasi dan komunikasi sangat dibutuhkan dalam kehidupan manusia. Karena dua hal tersebut sering digunakan untuk mempermudah pekerjaan manusia. Bisnis transportasi adalah salah satu jasa yang saat ini sangat dibutuhkan masyarakat. Pemberian jasa transportasi yang baik sangat dibutuhkan masyarakat. Perusahaan jasa dalam kegiatan pemasarannya dapat dibedakan dengan tiga cara yaitu 3P dari pemasaran jasa, yaitu lewat personal (personel), lingkungan fisik (physical environment), dan 
proses manajemen (process management) [1]. Kecanggihan alat transportasi di abad 21 tidak dapat terbendung lagi. Hal ini terbukti dengan adanya berbagai bidang seperti dari bidang komunikasi. Pemanfaatan teknologi bukan hanya dibidang komunikasi saja tetapi teknologi dimanfaatkan pada bidang pendidikan, ekonomi, pertanian, keamanan, transportasi dan lain-lain Perkembangan zaman yang makin pesat, semakin hari manusia semakin kreatif dan inovatif menciptakan bisnis baru, terutama bisnis yang menyediakan jasa transportasi. Semakin banyaknya transportasi online mempunyai dampak semakin ketatnya persaingan. Faktor yang menjadi penyebab terjadinya hal tersebut yakni adanya persaingan harga dan banyaknya alternatif pilihan jasa tranportasi online. Hal ini menjadikan konsumen semakin selektif. Konsumen akan memilih salah satu diantara pilihan alternatif yang menurutnya sesuai dengan yang diinginkan. Mengantisipasi keadaan tersebut maka perusahaan transportasi online harus bisa menciptakan kepuasan pelanggan

Kualitas pelayanan yang baik dapat menjadi keunggulan bersaing bagi perusahaan jasa. Kualitas pelayanan juga merupakan kunci untuk mencapai kesuksesan. Terdapat lima faktor yang dapat mempengaruhi kualitas layanan Tangibles, Reliability, Responsiveness, Assurance dan Emphaty [2]. Baik tidaknya kualitas pelayanan barang atau jasa tergantung pada kemampuan produsen dalam memenuhi harapan konsumen secara konsisten. Model kualitas jasa yang menyoroti syarat-syarat utama untuk memberikan kualitas jasa yang mengidentifikasikan 5 kesenjangan yang mengakibatkan kegagalan dalam penyampaian jasa, yaitu (1) Kesenjangan antara harapan konsumen dan persepsi manajemen. (2) Kesenjangan antara persepsi manajemen dan spesifikasi kualitas jasa. (3) Kesenjangan antara spesifikasi kualitas jasa dan penyampaian jasa. (4) Kesenjangan antara penyampaian jasa dan konsumen ekstemal. (5) Kesenjangan antara jasa yang dialami dan jasa yang diharapkan [3].

Kualitas pelayanan dikatakan memuaskan jika layanan yang dirasakan sama atau melebihi kualitas pelayanan yang diharapkan. Pelayanan yang seperti inilah yang dipersepsikan sebagai pelayanan berkualitas dan memuaskan. Harapan konsumen tersebut tercermin pada pelayanan yang baik, ramah tamah, sopan santun, ketepatan waktu, dan kecepatan menjadi nilai penting yang diharapkan oleh para konsumen. Kosumen yang merasa puas secara tidak langsung akan mendorong terjadinya rekomendasi dari mulut ke mulut, bahkan dapat memperbaiki citra perusahaan di mata konsumen. Oleh karena itu, kualitas pelayanan harus menjadi fokus utama perhatian perusahaan karena dapat menciptakan kepuasan pelanggan.

Kano [4] [5] [6] mengemukakan terdapat dua aspek untuk tiap atribut kualitas yaitu aspek objektif yang melibatkan pemenuhan kualitas dan aspek subjektif melibatkan persepsi konsumen atas kepuasan. Kedua aspek ini dituangkan dalam sebuah model yang dikenal sebagai model Kano (Gambar 1).

Dalam metode Kano, kategori dari suatu produk dapat dibedakan menjadi [4] [5]:

1. Must-be atau Basic needs atau Thereshold : pelanggan tidak puas apabila kinerja dari atribut yang bersangkutan rendah. Tetapi kepuasan pelanggan tidak akan meningkat jauh diatas netral meskipun kinerja dari atribut tersebut tinggi.

2. One dimensional atau performance needs atau linear: tingkat kepuasan pelanggan berhubungan linier dengan kinerja atribut, sehingga kinerja atribut yang tinggi akan mengakibatkan tingginya kepuasan pelanggan pula.

3. Attractive atau Excitement needs atau delighters: tingkat kepuasan pelanggan akan meningkat sangat tinggi dengan meningkatnya kinerja atribut. Akan tetapi penurunan kinerja atribut tidak akan menyebabkan penurunan tingkat kepuasan.

4. Reverse apabila tingkat kepuasan pelanggan berbanding terbalik dengan hasil kinerja atribut, Questionable Result apabila tingkat kepuasan pelanggan tidak dapat didefinisikan (terdapat kontradiksi pada jawaban pelanggan) atau Indifferent apabila tingkat kepuasan pelanggan tidak berpengaruh dari hasil kinerja atribut.

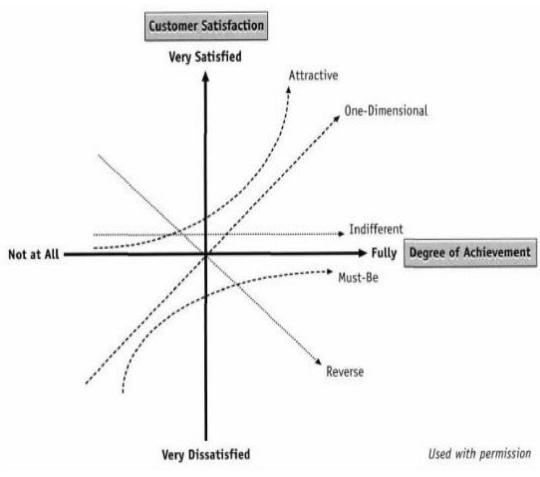

Gambar 1. Model Kano 


\section{METODE PENELITIAN}

Pengumpulan data dilakukan dengan survei pada konsumen pengguna jasa transportasi online. Pemilihan objek penelitian dilakukan secara sengaja (purposive) [7]. dengan pertimbangan bahwa makin lama banyak perusahaan yang bergerak dibidang transportasi online. Selain itu juga digunakan data sekunder untuk mendukung penelitian ini

Metode Servqual digunakan untuk mengukur kualitas layanan. Dalam metode Servqual terdapat lima faktor utama atau dimensi Servqual yang menentukan kualitas pelayanan, yaitu Tangible, Reliability, Responsiveness, Assurance dan Empathy [2]. Metode Servqual ini mendefinisikan bahwa kesenjangan (G) untuk faktor kualitas jasa atau pelayanan tertentu adalah :

$$
\mathrm{G}=\mathrm{P}(\text { Perceptions })-\mathrm{E}(\text { Expectations })
$$

Untuk menganalisa kualitas pelayanan yang diberikan digunakan rumus :

$$
\text { Kualitas } Q=\frac{\text { Penilaian }}{\text { Harapan }}
$$

Jika kualitas $(\mathrm{Q}) \geq 1$, maka kualitas pelayanan dikatakan baik. Dengan metode Servqual dapat diketahui kepuasan konsumen terhadap kualitas pelayanan yang diberikan oleh transportasi online ditinjau dari harapan para pelanggan.

Berdasarkan fungsionalitas sistem informasi, dibuatlah kuisioner Kano yang kemudian disebar kepada responden yang merupakan pengguna transportasi online. [8]

Selanjutnya dilakukan pengukuran kualitas dengan model Kano. Langkah-langkah pengukuran kualitas layanan dengan metode kano yang sudah diadaptasikan dengan metode servqual yaitu dengan mengklasifikasi atribut berdasarkan metode Kano

1. Menentukan kategori atribut tiap responden berdasarkan tabel kategori kano

\begin{tabular}{|c|c|c|c|c|c|c|}
\hline \multirow{2}{*}{\multicolumn{2}{|c|}{ Kebutuhan Konsumen }} & \multicolumn{5}{|c|}{ Disfungsional } \\
\hline & & 1 & 2 & 3 & 4 & 5 \\
\hline & & 1.like & 2.must be & 3. neutral & 4.live with & 5. dislike \\
\hline & 1.like & $\mathrm{Q}$ & $\mathrm{A}$ & $\mathrm{A}$ & $\mathrm{A}$ & $\mathrm{O}$ \\
\hline 馬 & 2.must be & $\mathrm{R}$ & I & I & I & M \\
\hline$\cdot \frac{\bar{\sigma}}{n}$ & 3.neutal & $\mathrm{R}$ & I & $\mathrm{I}$ & I & M \\
\hline$\stackrel{60}{\equiv}$ & 4.live with & $\mathrm{R}$ & I & I & I & M \\
\hline 㞋 & 5.dislike & $\mathrm{R}$ & $\mathrm{R}$ & $\mathrm{R}$ & $\mathrm{R}$ & Q \\
\hline
\end{tabular}

Tabel 1. Evaluasi Kano

Keterangan :

$\mathrm{Q}=$ Questionable $($ Diragukan $)$

$\mathrm{R}=$ Reverse (Kemunduran)

$\mathrm{A}=$ Attractive (Menarik)

$\mathrm{I}=$ Indefferent $($ Netral)

$\mathrm{O}=$ One Dimensional (Satu Ukuran)

$\mathrm{M}=$ Must be (Keharusan)

2. Menghitung jumlah masing-masing kategori kano dalam tap-tiap atribut.

3. Menentukan kategori kano tiap atribut dengan menggunakan Baluth's Formula (Walden) sebagai berikut :

a. Jika jumlah nilai (one dimensional + attractive + must be $)>$ jumlah niai (Indifferent + reverse + questionable) maka grade diperoleh nilai paling maksimum dari (one dimensional,attractive ,must be)

b. Jika jumlah nilai (one dimensional + attractive + must be $)<$ jumlah niai $($ Indifferent + reverse + questionable) maka grade diperoleh nilai paling maksimum dari (indifferent,reverse, questionable)

\section{HASIL DAN PEMBAHASAN}

\subsection{Kesenjangan Harapan dan Diterima Pelanggan}

Data kesenjangan dan harapan yang diterima pelanggan dibutuhkan untuk menetapkan prioritas perhatian terhadap atribut layanan yang diharapkan untuk ditingkatkan. Nilai kesenjangan (gap) adalah selisih antara nilai yang diterima dengan nilai harapan. Selengkapnya kondisi kesenjangan setiap atribut layanan transportasi online dapat dilihat pada Tabel 2. 
Tabel 2. Kesenjangan Atribut Pelayanan Transportasi Online

\begin{tabular}{|c|c|c|c|c|}
\hline No & Pernyataan & Kenyataan & Harapan & Kesenjangan \\
\hline \multicolumn{5}{|c|}{ I. VARIABEL KUALITAS PELAYANAN } \\
\hline \multicolumn{5}{|c|}{$\begin{array}{l}\text { BUKTI FISIK (TANGIBLE) } \\
\end{array}$} \\
\hline 1. & Penampilan pengendara OJOL (MOTOR) bersih dan rapi & 3,44 & 4,29 & -0.85 \\
\hline 2. & Atribut berkendara seperti Helm dan Jaket bersih & 3,34 & 4,26 & -0.92 \\
\hline 3. & Atribut berkendara lengkap & 3,50 & 4,28 & -0.78 \\
\hline 4. & Atribut kendaraan lengkap & 3,56 & 4,28 & -0.72 \\
\hline 5. & Kendaraan layak digunakan & 3,63 & 4,29 & -3.66 \\
\hline \multicolumn{5}{|c|}{ EMPATI (EMPHATY) } \\
\hline 1 & $\begin{array}{l}\text { Setiap menggunakan layanan OJOL (MOTOR) driver } \\
\text { berperilaku ramah. }\end{array}$ & 3,61 & 4,30 & -0.69 \\
\hline 2. & $\begin{array}{l}\text { Driver OJOL (MOTOR) mau mengerti kebutuhan } \\
\text { pelanggan.. }\end{array}$ & 3,61 & 4,23 & -0.62 \\
\hline 3. & $\begin{array}{l}\text { Driver bersedia meminjamkan jaket atau jas hujan pada saat } \\
\text { konsumen membutuhkan. }\end{array}$ & 3,49 & 4,28 & -0.79 \\
\hline 4. & Driver mampu menjaga hubungan baik dengan konsumen. & 3,60 & 4,32 & -0.72 \\
\hline \multicolumn{5}{|c|}{\begin{tabular}{|l} 
DAYA TANGGAP \\
\end{tabular}} \\
\hline 1 & $\begin{array}{l}\text { Driver OJOL (MOTOR) cepat dalam merespon keinginan } \\
\text { konsumen. }\end{array}$ & 3,61 & 4,26 & -0.65 \\
\hline 2. & $\begin{array}{l}\text { Driver OJOL (MOTOR) menunjukkan kesungguhan dalam } \\
\text { melayani keluhan pelanggan. }\end{array}$ & 3,66 & 4,24 & -0.58 \\
\hline 3. & $\begin{array}{l}\begin{array}{l}\text { Driver bersifat sopan terhadap konsumen } \\
\text { konsumen menggunakan jasa OJOL }\end{array} \text { (MOTOR) } \\
\end{array}$ & 3,61 & 4,24 & -0.63 \\
\hline \multicolumn{5}{|c|}{ KEHANDALAN } \\
\hline 1. & Driver mengantarkan ke lokasi yang dituju dengan efisien. & 3,56 & 4,30 & -0.74 \\
\hline 2. & Driver mengemudikan kendaraan dengan baik. & 3,54 & 4,28 & -0.74 \\
\hline 3. & Driver selalu mematuhi peraturan lalu lintas. & 3,61 & 4,34 & -0.73 \\
\hline 4. & $\begin{array}{l}\text { Driver mengutamakan kenyamanan konsumen pada saat } \\
\text { mengantarkan konsumen ke tempat tujuan. }\end{array}$ & 3,43 & 4,34 & -0.91 \\
\hline 5. & $\begin{array}{l}\text { Driver menguasai jalan dan daerah yang akan dituju oleh } \\
\text { konsumen. }\end{array}$ & 3,35 & 4,38 & -1.03 \\
\hline \multicolumn{5}{|c|}{$\begin{array}{l}\text { JAMINAN } \\
\end{array}$} \\
\hline 1. & $\begin{array}{lrrrr}\text { OJOL (motor) memberikan jaminan keamanan dan } \\
\text { keselamatan kepada konsumen }\end{array}$ & 3,70 & 4,40 & -0.70 \\
\hline 2. & $\begin{array}{l}\text { OJOL (motor) menjaga kerahasiaan nomor ponsel } \\
\text { konsumen }\end{array}$ & 3,66 & 4,35 & -0.69 \\
\hline \multicolumn{5}{|c|}{ II. VARIABEL HARGA } \\
\hline 1. & Tarif OJOL (MOTOR) terjangkau & 3,63 & 4,49 & -0.86 \\
\hline 2. & $\begin{array}{l}\text { Tarif OJOL (MOTOR) sesuai dengan pelayanan yang } \\
\text { diterima oleh konsumen }\end{array}$ & 3,61 & 4,41 & -0.80 \\
\hline \multicolumn{5}{|c|}{ III. VARIABEL LOYALITAS PELANGGAN } \\
\hline 1. & $\begin{array}{l}\text { Saya bersedia menggunakan jasa OJOL (MOTOR) lagi di } \\
\text { kemudian hari }\end{array}$ & 3,61 & 3,39 & 0.22 \\
\hline 2. & $\begin{array}{l}\begin{array}{l}\text { Saya akan menyarankan kepada orang } \\
\text { menggunakan } \text { lain }\end{array} \text { untuk } \\
\text { lainnya }\end{array}$ & 3,60 & 3,59 & 0.01 \\
\hline
\end{tabular}

\subsection{Pengolahan Model Kano}

Dari hasil perhitungan dan analisa pengklasifikasian kategori Kano maka diperoleh jumlah/ nilai kategori kano tiap-tiap atribut terhadap semua responden seperti pada Tabel 3.

Tabel 3. Pemetaan Kategori Kano Untuk Setiap Atribut Pelayanan

\begin{tabular}{|c|l|c|c|c|c|c|c|c|}
\hline No & \multicolumn{1}{|c|}{ Pernyataan } & & & & & & & \\
\hline I. VARIABEL KUALITAS PELAYANAN & & & & & & & \\
\hline \multicolumn{1}{|c|}{ BUKTI FISIK (TANGIBLE) } & O & A & M & I & R & Q & TOT \\
\hline 1. & $\begin{array}{l}\text { Penampilan pengendara OJOL (MOTOR) bersih dan } \\
\text { rapi }\end{array}$ & 22 & 25 & 20 & 26 & 1 & 0 & 94 \\
\hline 2. & Atribut berkendara seperti Helm dan Jaket bersih & 30 & 26 & 18 & 20 & 0 & 0 & 94 \\
\hline 3. & Atribut berkendara lengkap & 22 & 25 & 20 & 26 & 1 & 0 & 94 \\
\hline 4. & Atribut kendaraan lengkap & 20 & 26 & 18 & 30 & 0 & 0 & 94 \\
\hline
\end{tabular}


Tabel 3. Pemetaan Kategori Kano Untuk Setiap Atribut Pelayanan (lanjutan)

\begin{tabular}{|c|c|c|c|c|c|c|c|c|}
\hline No & Pernyataan & & & & & & & \\
\hline \multicolumn{9}{|c|}{ I. VARIABEL KUALITAS PELAYANAN } \\
\hline \multicolumn{2}{|c|}{ BUKTI FISIK (TANGIBLE) } & $\mathbf{O}$ & $\mathbf{A}$ & $\mathbf{M}$ & I & $\mathbf{R}$ & $\mathbf{Q}$ & TOT \\
\hline 5. & Kendaraan layak digunakan & 22 & 25 & 20 & 26 & 1 & 0 & 94 \\
\hline \multicolumn{9}{|c|}{ EMPATI (EMPHATY) } \\
\hline 1 & $\begin{array}{l}\text { Setiap menggunakan layanan OJOL (MOTOR) driver } \\
\text { berperilaku ramah. }\end{array}$ & 20 & 25 & 18 & 30 & 0 & 0 & 94 \\
\hline 2. & $\begin{array}{l}\text { Driver OJOL (MOTOR) mau mengerti kebutuhan } \\
\text { pelanggan.. }\end{array}$ & 27 & 25 & 20 & 22 & 1 & 0 & 94 \\
\hline 3. & $\begin{array}{l}\text { Driver bersedia meminjamkan jaket atau jas hujan } \\
\text { pada saat konsumen membutuhkan. }\end{array}$ & 31 & 25 & 18 & 20 & 0 & 0 & 94 \\
\hline 4. & $\begin{array}{l}\text { Driver mampu menjaga hubungan baik dengan } \\
\text { konsumen. }\end{array}$ & 26 & 25 & 20 & 22 & 1 & 0 & 94 \\
\hline \multicolumn{9}{|c|}{ DAYA TANGGAP } \\
\hline 1 & $\begin{array}{l}\text { Driver OJOL (MOTOR) cepat dalam merespon } \\
\text { keinginan konsumen. }\end{array}$ & 22 & 26 & 20 & 29 & 0 & 0 & 94 \\
\hline 2. & $\begin{array}{l}\text { Driver OJOL (MOTOR) menunjukkan kesungguhan } \\
\text { dalam melayani keluhan pelanggan. }\end{array}$ & 26 & 25 & 20 & 22 & 1 & 0 & 94 \\
\hline 3. & $\begin{array}{l}\text { Driver bersifat sopan terhadap konsumen pada saat } \\
\text { konsumen menggunakan jasa OJOL (MOTOR) }\end{array}$ & 32 & 24 & 15 & 23 & 0 & 0 & 94 \\
\hline \multicolumn{9}{|c|}{ KEHANDALAN } \\
\hline 1. & $\begin{array}{l}\text { Driver mengantarkan ke lokasi yang dituju dengan } \\
\text { efisien. }\end{array}$ & 22 & 25 & 20 & 26 & 1 & 0 & 94 \\
\hline 2. & Driver mengemudikan kendaraan dengan baik. & 30 & 26 & 18 & 20 & 0 & 0 & 94 \\
\hline 3. & Driver selalu mematuhi peraturan lalu lintas. & 26 & 25 & 20 & 22 & 1 & 0 & 94 \\
\hline 4. & $\begin{array}{l}\text { Driver mengutamakan kenyamanan konsumen pada } \\
\text { saat mengantarkan konsumen ke tempat tujuan. }\end{array}$ & 31 & 26 & 15 & 22 & 0 & 0 & 94 \\
\hline 5. & $\begin{array}{l}\text { Driver menguasai jalan dan daerah yang akan dituju } \\
\text { oleh konsumen. }\end{array}$ & 26 & 25 & 20 & 22 & 1 & 0 & 94 \\
\hline \multicolumn{9}{|c|}{ JAMINAN } \\
\hline 1. & $\begin{array}{l}\text { OJOL (motor) memberikan jaminan keamanan dan } \\
\text { keselamatan kepada konsumen }\end{array}$ & 34 & 26 & 18 & 16 & 0 & 0 & 94 \\
\hline 2. & $\begin{array}{l}\text { OJOL (motor) menjaga kerahasiaan nomor ponsel } \\
\text { konsumen }\end{array}$ & 26 & 25 & 20 & 22 & 1 & 0 & 94 \\
\hline \multicolumn{9}{|c|}{ II. VARIABEL HARGA } \\
\hline 1. & Tarif OJOL (MOTOR) terjangkau & 20 & 26 & 18 & 30 & 0 & 0 & 94 \\
\hline 2. & $\begin{array}{l}\text { Tarif OJOL (MOTOR) sesuai dengan pelayanan yang } \\
\text { diterima oleh konsumen }\end{array}$ & 25 & 23 & 24 & 21 & 1 & 0 & 94 \\
\hline \multicolumn{9}{|c|}{ III. VARIABEL LOYALITAS PELANGGAN } \\
\hline 1. & $\begin{array}{l}\text { Saya bersedia menggunakan jasa OJOL (MOTOR) } \\
\text { lagi di kemudian hari }\end{array}$ & 20 & 26 & 18 & 30 & 0 & 0 & 94 \\
\hline 2. & $\begin{array}{l}\text { Saya akan menyarankan kepada orang lain untuk } \\
\text { menggunakan OJOL (MOTOR) daripada ojek online } \\
\text { lainnya }\end{array}$ & 22 & 25 & 20 & 26 & 1 & 0 & 94 \\
\hline
\end{tabular}

Setelah didapatkan jumlah/nilai kategori Kano tiap-tiap atribut terhadap semua responden maka dilakukan penentuan kategori Kano dengan menggunakan rumus Blauth's formula, seperti rumus diatas sehingga dihasilkan kategori Kano seperti Tabel 4.

Tabel 4. Hasil Kategori Kano Untuk Setiap Atribut Pelayanan

\begin{tabular}{|c|l|c|}
\hline No & \multicolumn{1}{|c|}{ Pernyataan } & Kategori Kano \\
\hline \multicolumn{1}{|c|}{ I. VARIABEL KUALITAS PELAYANAN } & \\
\hline \multicolumn{1}{|c|}{ BUKTI FISIK (TANGIBLE) } & I \\
\hline 1. & Penampilan pengendara OJOL (MOTOR) bersih dan rapi & O \\
\hline. & Atribut berkendara seperti Helm dan Jaket bersih & I \\
\hline 3. & Atribut berkendara lengkap & I \\
\hline 4. & Atribut kendaraan lengkap & I \\
\hline 5. & Kendaraan layak digunakan & \\
\hline
\end{tabular}


Tabel 4. Hasil Kategori Kano Untuk Setiap Atribut Pelayanan (lanjutan)

\begin{tabular}{|c|c|c|}
\hline No & Pernyataan & Kategori Kano \\
\hline \multicolumn{3}{|c|}{ I. VARIABEL KUALITAS PELAYANAN } \\
\hline \multicolumn{3}{|c|}{$\begin{array}{l}\text { BUKTI FISIK (TANGIBLE) } \\
\end{array}$} \\
\hline 1. & Penampilan pengendara OJOL (MOTOR) bersih dan rapi & $\mathrm{I}$ \\
\hline & Atribut berkendara seperti Helm dan Jaket bersih & $\mathrm{O}$ \\
\hline 3. & Atribut berkendara lengkap & $\mathrm{I}$ \\
\hline 4. & Atribut kendaraan lengkap & I \\
\hline 5. & Kendaraan layak digunakan & I \\
\hline \multicolumn{3}{|c|}{ EMPATI (EMPHATY) } \\
\hline 1 & Setiap menggunakan layanan OJOL (MOTOR) driver berperilaku ramah. & I \\
\hline 2. & Driver OJOL (MOTOR) mau mengerti kebutuhan pelanggan.. & $\mathrm{O}$ \\
\hline 3. & $\begin{array}{l}\text { Driver bersedia meminjamkan jaket atau jas hujan pada saat konsumen } \\
\text { membutuhkan. }\end{array}$ & $\mathrm{O}$ \\
\hline 4. & Driver mampu menjaga hubungan baik dengan konsumen. & $\mathrm{O}$ \\
\hline \multicolumn{3}{|c|}{ DAYA TANGGAP } \\
\hline 1 & Driver OJOL (MOTOR) cepat dalam merespon keinginan konsumen. & $\mathrm{I}$ \\
\hline 2. & $\begin{array}{l}\text { Driver OJOL (MOTOR) menunjukkan kesungguhan dalam melayani keluhan } \\
\text { pelanggan. }\end{array}$ & $\mathrm{O}$ \\
\hline 3. & $\begin{array}{l}\text { Driver bersifat sopan terhadap konsumen pada saat konsumen menggunakan jasa } \\
\text { OJOL (MOTOR) }\end{array}$ & $\mathrm{O}$ \\
\hline \multicolumn{3}{|c|}{ KEHANDALAN } \\
\hline 1. & Driver mengantarkan ke lokasi yang dituju dengan efisien. & I \\
\hline 2. & Driver mengemudikan kendaraan dengan baik. & $\mathrm{O}$ \\
\hline 3. & Driver selalu mematuhi peraturan lalu lintas. & $\mathrm{O}$ \\
\hline 4. & $\begin{array}{l}\text { Driver mengutamakan kenyamanan konsumen pada saat mengantarkan konsumen } \\
\text { ke tempat tujuan. }\end{array}$ & $\mathrm{O}$ \\
\hline 5. & Driver menguasai jalan dan daerah yang akan dituju oleh konsumen. & $\mathrm{O}$ \\
\hline \multicolumn{3}{|c|}{ JAMINAN } \\
\hline 1. & OJOL (motor) memberikan jaminan keamanan dan keselamatan kepada konsumen & $\mathrm{O}$ \\
\hline 2. & OJOL (motor) menjaga kerahasiaan nomor ponsel konsumen & $\mathrm{O}$ \\
\hline \multicolumn{3}{|c|}{ II. VARIABEL HARGA } \\
\hline 1. & Tarif OJOL (MOTOR) terjangkau & I \\
\hline 2. & Tarif OJOL (MOTOR) sesuai dengan pelayanan yang diterima oleh konsumen & $\mathrm{O}$ \\
\hline \multicolumn{3}{|c|}{ III. VARIABEL LOYALITAS PELANGGAN } \\
\hline 1. & Saya bersedia menggunakan jasa OJOL (MOTOR) lagi di kemudian hari & I \\
\hline 2. & $\begin{array}{l}\text { Saya akan menyarankan kepada orang lain untuk menggunakan OJOL (MOTOR) } \\
\text { daripada ojek online lainnya }\end{array}$ & I \\
\hline
\end{tabular}

\section{SIMPULAN}

Dengan metode ServQual didapatkan bahwa gap skor untuk 21 atribut layanan yang diukur dalam penelitian ini menghasilkan nilai yang negatif, dan 2 atribut pelayanan menghasilkan nilai positif. artinya seluruh pelayanan yang sudah dilakukan oleh perusahaan dinilai masih belum sesuai dengan harapan pelanggan mereka

Integrasi Kano model ke dalam ServQual berimplikasi pada perubahan yang berarti juga terjadi perubahan prioritas urutan atribut pelayanan yang perlu diperbaiki. Terdapat 13 atribut pelayanan transportasi online yang perlu di-improve yaitu atribut yang merupakan irisan antara 'weak attributes' yang didapatkan dari perhitungan ServQual dengan yang berkategori 'attractive', 'one-dimensional' dan "must be". Atribut tersebut adalah Atribut berkendara seperti Helm dan Jaket bersih, Driver OJOL (MOTOR) mau mengerti kebutuhan pelanggan, Driver bersedia meminjamkan jaket atau jas hujan pada saat konsumen membutuhkan, Driver mampu menjaga hubungan baik dengan konsumen, Driver OJOL (MOTOR) menunjukkan kesungguhan dalam melayani keluhan pelanggan, Driver bersifat sopan terhadap konsumen pada saat konsumen, Driver mengemudikan kendaraan dengan baik, Driver selalu mematuhi peraturan lalu lintas, Driver mengutamakan kenyamanan konsumen pada saat mengantarkan konsumen ke tempat tujuan, Driver menguasai jalan dan daerah yang akan dituju oleh konsumen, OJOL (motor) memberikan jaminan keamanan dan keselamatan kepada konsumen, OJOL (motor) menjaga kerahasiaan nomor ponsel konsumen, Tarif OJOL (MOTOR) sesuai dengan pelayanan yang diterima oleh konsumen. 


\section{DAFTAR PUSTAKA}

[1] Kottler, Philip. (1997). Manajemen Pemasaran : Analisis, Perencanaan, Implementasi dan Kontrol, Jilid $1 \&$ 2, Jakarta, Prehallindo.

[2] Tjiptono, Fandi. (2001). Strategi Pemasaran, Yogyakarta, Andi Offset.

[3] Parasuraman, A. Valeri, A. Zeithmal. Berry, L. Leonard (1990). Delivering Quality Service, Balancing, Customer Perception and Expectation, New York, The Free Press.

[4] Berger, C. et al. 1993. Kano's Method for Understanding Customer - Defined Quality. Center for Quality Management Journal, (fall), 3-35.

[5] Kano, N. et al. (1996). Attractive Quality and Must-be Quality. The Best On Quality, 7.

[6] Matzler, K. \& Hinterhuber, H. H. 1996. How to make product development projects more successful by integrating Kano's model of customer satisfaction into quality function deployment. Technoation 18. 1, 25-37.

[7] Sugiyono. (2017). Metode Penelitian Kualitatif dan Kuantitatif, R\&D, Bandung, Alfabeta CV

[8] Robinson, C. 2009. Kano on Customer. The Journal for Quality and Participation 32. 2, 23-25. 